\title{
Commentary: Systemic effects of IL-17 in inflammatory arthritis
}

\author{
Pietro Enea Lazzerini ${ }^{1 *}$, Franco Laghi-Pasini ${ }^{1+}$, Mohamed Boutjdir ${ }^{2,3 \dagger}$ and \\ Pier Leopoldo Capecchi ${ }^{1+}$ \\ ${ }^{1}$ Department of Medical Sciences, Surgery and Neurosciences, University of Siena, Siena, Italy, ${ }^{2}$ VA New York Harbor \\ Healthcare System, SUNY Downstate Medical Center, New York, NY, United States, ${ }^{3}$ NYU School of Medicine, New York, \\ NY, United States
}

Keywords: IL-17, cardiac arrhythmias, inflammatory arthritis, structural remodeling, electric remodeling, connexin43

\section{A Commentary on}

Systemic effects of IL-17 in inflammatory arthritis

by Beringer, A., and Miossec, P. (2019). Nat. Rev. Rheumatol. 15:491-501. doi: 10.1038/ s41584-019-0243-5

\section{OPEN ACCESS}

Edited by:

Marina Cerrone,

New York University, United States

Reviewed by:

Michele Miragoli,

University of Parma, Italy

Laura Geraldino-Pardilla,

Columbia University, United States

*Correspondence:

Pietro Enea Lazzerini

lazzerini7@unisi.it

†These authors have contributed equally to this work

Specialty section:

This article was submitted to General Cardiovascular Medicine, a section of the journal Frontiers in Cardiovascular Medicine

Received: 28 October 2019 Accepted: 25 November 2019 Published: 10 December 2019

Citation:

Lazzerini PE, Laghi-Pasini F, Boutjdir M and Capecchi PL (2019)

Commentary: Systemic effects of IL-17 in inflammatory arthritis. Front. Cardiovasc. Med. 6:183. doi: 10.3389/fcvm.2019.00183
The recent article by Beringer and Miossec (1) provided a detailed examination of the pleiotropic effects of interleukin-17 (IL-17), highlighting their potential role in promoting systemic co-morbidities in inflammatory arthritis (IA). In particular, given the increased cardiovascular risk characterizing these patients, Beringer and Miossec extensively discussed how the effects of IL-17 on blood vessels and heart might accelerate atherosclerosis and related complications, as well as hypertension and cardiomyopathy development (1).

However, the authors did not mention a number of recent studies suggesting a significant impact of IL-17 on the arrhythmic risk. This aspect should be emphasized as cardiac arrhythmias, particularly ventricular arrhythmias (VA) and cardiac arrest, atrial fibrillation (AF) and conduction disturbances, are more commonly observed in IA than in the general population, significantly contributing to morbidity and mortality (2-5). Although the underlying mechanisms are probably complex, increasing evidence points to a key role for systemic inflammation, at least in part via direct effects of cytokines, specifically TNF $\alpha$, IL- 6 and IL-1, able to induce cardiac remodeling both structural (damage/fibrosis promoting re-entry mechanisms) (2), and electric by modulating the expression/function of specific ion channels in the cardiomyocyte (inflammatory cardiac channelopathies) $(6,7)$. Such channels also include gap-junctions, intercellular channels mediating electrical coupling between two adjacent cardiomyocytes, formed by proteins named connexins (Cxs). Among different connexins, Cx43 is ubiquitously expressed in the heart where critically contributes to impulse conduction velocity and refractoriness heterogeneity in ventricles, atria and atrio-ventricular (AV) junction (8-10). Evidence indicates that TNF $\alpha$, IL-6, and IL-1 can promote arrhythmias by inhibiting cardiac Cx43 expression $(6,7,11)$. In this scenario, IL-17 might play an important additional role.

By using the Langendorff perfusion model, Chang et al. (12) demonstrated that acute administration of IL-17 can induce VA in rabbit hearts, along with decreasing conduction velocity and prolonging action potential duration, all these changes being prevented by perfusion with an anti-IL-17 neutralizing antibody. The same authors demonstrated that VAs inducibility was also significantly increased in a rabbit model of ischemic heart failure following chronic intravenous administration of IL-17. In the left ventricle of these animals, collagen production, fibrosis and apoptosis were markedly enhanced (12). Moreover, in rats with myocardial infarction, reduced 




FIGURE 1 | Putative pro-arrhythmic effects of IL-17. Systemically released IL-17 can promote arrhythmogenesis by affecting different cells in the heart. Cardiac fibroblast are stimulated by IL-17 to produce high amounts of collagen with tissue fibrosis, resulting in structural remodeling. IL-17 can also induce electric remodeling by down-regulating connexin43 (Cx43) expression, possibly in both cardiomyocytes and cardiac macrophages. Remodeling phenomena are responsible for decrease/heterogeneity of electric impulse conduction velocity throughout the working and conducting myocardium, in turn promoting re-entry-driven tachyarrhythmias and conduction disturbances.

IL-17 expression in the myocardium was associated with increased $\mathrm{Cx} 43$ expression, and lower susceptibility to VAs induction upon programmed electrical stimulation (13).

\section{REFERENCES}

1. Beringer A, Miossec P. Systemic effects of IL-17 in inflammatory arthritis. Nat Rev Rheumatol. (2019) 15:491-501. doi: 10.1038/s41584-019-0243-5

2. Lazzerini PE, Capecchi PL, Laghi-Pasini F. Systemic inflammation and arrhythmic risk: lessons from rheumatoid arthritis. Eur Heart J. (2017) 38:1717-27. doi: 10.1093/eurheartj/ehw208
Furthermore, the group of Saffitz showed the implication of IL-17 in disruption of desmosomal proteins, i.e., translocation of plakoglobin from cell-cell junction resulting in granulomatous myocarditis as potential pathogenic links to arrhythmogenic right ventricular cardiomyopathy (ARVC) (14). Notably, in ARVC, where $\mathrm{Cx} 43$ expression has been reported to be reduced $(15,16)$, myocardial IL-17 level is increased. Interleukin-17A levels are also elevated in patients with AF (17), and treatment with anti-IL-17A monoclonal antibody markedly suppressed AF development in a rat model of sterile pericarditis, concomitantly reducing atrial inflammation and fibrosis (18). Finally, a recent genome-wide association study identified a single-nucleotide-polymorphism in the gene encoding IL-17D as a key determinant of electric conduction in the AV node (19). This finding intriguingly suggests a pathogenic role for IL-17 in $\mathrm{AV}$ disturbances observed in IA, possibly by modulating Cx43 expression on myocytes and/or macrophages in the AV node (9).

Altogether, these data point to a significant involvement of IL-17 in arrhythmogenesis (Figure 1). Further research is warranted to better dissect its specific role in cardiac electrophysiology, as well as the potential beneficial effects of IL-17 targeted therapies on arrhythmic disorders in IA. In this regard, two anti-IL-17 agents are currently approved for IA (specifically psoriatic arthritis), i.e., secukinumab and ixekizumab (20). However, although numerous randomized controlled trials demonstrated the cardiovascular safety of these drugs $(20,21)$, to date no specific information is available on their impact on arrhythmic events in IA patients.

\section{AUTHOR CONTRIBUTIONS}

PL: conception, design, and drafting of the work. FL-P, MB, and PC: revising the draft of the work critically for important intellectual content and agreement to be accountable for all aspects of the work in ensuring that questions related to the accuracy or integrity of any part of the work are appropriately investigated and resolved. PL, FL-P, MB, and PC: final approval of the version to be published.

\section{FUNDING}

This commentary was funded by Ministero dell'Istruzione, dell'Università e della Ricerca (MIUR), Progetti di Rilevante Interesse Nazionale (PRIN), and Bando 2017, protocollo 2017XZMBYX. 
a register-based study from Sweden. Ann Rheum Dis. (2018) 77:541-8. doi: 10.1136/annrheumdis-2017-212189

5. Lazzerini PE, Laghi Pasini F, Acampa M, Capecchi PL. Inflammatory cytokines, life-threatening arrhythmias and premature mortality in chronic inflammatory arthritis: time to focus on. Ann Rheum Dis. (2019) 78:e98. doi: 10.1136/annrheumdis-2018-213789

6. Lazzerini PE, Capecchi PL, El-Sherif N, Laghi-Pasini F, Boutjdir M. Emerging arrhythmic risk of autoimmune and inflammatory cardiac channelopathies. $J$ Am Heart Assoc. (2018) 7:e010595. doi: 10.1161/JAHA.118.0 10595

7. Lazzerini PE, Laghi-Pasini F, Boutjdir M, Capecchi PL. Cardioimmunology of arrhythmias: the role of autoimmune and inflammatory cardiac channelopathies. Nat Rev Immunol. (2019) 19:63-4. doi: 10.1038/s41577-018-0098-z

8. Severs NJ, Bruce AF, Dupont E, Rothery S. Remodelling of gap junctions and connexin expression in diseased myocardium. Cardiovasc Res. (2008) 80:9-19. doi: $10.1093 / \mathrm{cvr} / \mathrm{cvn} 133$

9. Hulsmans M, Clauss S, Xiao L, Aguirre AD, King KR, Hanley A., et al. Macrophages Facilitate Electrical Conduction in the Heart. Cell. (2017) 169:510-22.e520. doi: 10.1016/j.cell.2017.03.050

10. Swirski FK, Nahrendorf M. Cardioimmunology: the immune system in cardiac homeostasis and disease. Nat Rev Immunol. (2018) 18:733-44. doi: 10.1038/s41577-018-0065-8

11. Lazzerini PE, Laghi-Pasini F, Acampa M, Srivastava U, Bertolozzi I, Giabbani B, et al. Systemic inflammation rapidly induces reversible atrial electrical remodeling: the role of interleukin-6-mediated changes in connexin expression. J Am Heart Assoc. (2019) 8:e011006. doi: 10.1161/JAHA.118.011006

12. Chang SL, Hsiao YW, Tsai YN, Lin SF, Liu SH, Lin YJ., et al. Interleukin-17 enhances cardiac ventricular remodeling via activating MAPK pathway in ischemic heart failure. J Mol Cell Cardiol. (2018) 122:69-79. doi: 10.1016/j.yjmcc.2018.08.005

13. Chang HY, Li X, Tian Y. Telmisartan reduces arrhythmias through increasing cardiac connexin 43 by inhibiting IL-17 after myocardial infarction in rats. Eur Rev Med Pharmacol Sci. (2017) 21:5283-9. doi: 10.26355/eurrev_201711_13853

14. Asimaki A, Tandri H, Duffy ER, Winterfield JR, Mackey-Bojack S, Picken MM., et al. Altered desmosomal proteins in granulomatous myocarditis and potential pathogenic links to arrhythmogenic right ventricular cardiomyopathy. Circ Arrhythm Electrophysiol. (2011) 4:743-52. doi: 10.1161/CIRCEP.111.964890
15. Kaplan SR, Gard JJ, Protonotarios N, Tsatsopoulou A, Spiliopoulou C, Anastasakis A., et al. Remodeling of myocyte gap junctions in arrhythmogenic right ventricular cardiomyopathy due to a deletion in plakoglobin (Naxos disease). Heart Rhythm. (2004) 1:3-11. doi: 10.1016/j.hrthm.2004.01.001

16. Fidler LM, Wilson GJ, Liu F, Cui X, Scherer SW, Taylor GP., et al. Abnormal connexin 43 in arrhythmogenic right ventricular cardiomyopathy caused by plakophilin-2 mutations. J Cell Mol Med. (2009) 13:4219-28. doi: 10.1111/j.1582-4934.2008.00438.x

17. Nikoo MH, Taghavian SR, Golmoghaddam H, Arandi N, Abdi Ardakani A, Doroudchi M. Increased IL-17A in atrial fibrillation correlates with neutrophil to lymphocyte ratio. Iran J Immunol. (2014) 11:246-258. doi: 10.1016/j.atherosclerosis.2015.04.319

18. Fu XX, Zhao N, Dong Q, Du LL, Chen XJ, Wu QF, et al. Interleukin17A contributes to the development of post-operative atrial fibrillation by regulating inflammation and fibrosis in rats with sterile pericarditis. Int J Mol Med. (2015) 36:83-92. doi: 10.3892/ijmm.2015.2204

19. Verweij N, Mateo Leach I, van den Boogaard $M$, van Veldhuisen DJ, Christoffels VM., et al. Genetic determinants of $\mathrm{P}$ wave duration and PR segment. Circ Cardiovasc Genet. (2014) 7:475-81. doi: 10.1161/CIRCGENETICS.113.000373

20. Caiazzo G, Fabbrocini G, Di Caprio R, Raimondo A, Scala E, Balato N, et al. Psoriasis, cardiovascular events, and biologics: lights and shadows. Front Immunol. (2018) 9:1668. doi: 10.3389/fimmu.2018.01668

21. Champs B, Degboé Y, Barnetche T, Cantagrel A, Ruyssen-Witrand A, Constantin A. Short-term risk of major adverse cardiovascular events or congestive heart failure in patients with psoriatic arthritis or psoriasis initiating a biological therapy: a meta-analysis of randomised controlled trials. RMD Open. (2019) 5:e000763. doi: 10.1136/rmdopen-2018-0 00763

Conflict of Interest: The authors declare that the research was conducted in the absence of any commercial or financial relationships that could be construed as a potential conflict of interest.

Copyright ( 2019 Lazzerini, Laghi-Pasini, Boutjdir and Capecchi. This is an openaccess article distributed under the terms of the Creative Commons Attribution License (CC BY). The use, distribution or reproduction in other forums is permitted, provided the original author(s) and the copyright owner(s) are credited and that the original publication in this journal is cited, in accordance with accepted academic practice. No use, distribution or reproduction is permitted which does not comply with these terms. 